\title{
Are Joiners Trusters? A Panel Analysis of Participation and Generalized Trust
}

\section{Katrin Botzen}

University of Bern, Institute of Sociology, Fabrikstrasse 8, 3012 Bern, Switzerland.

katrin.botzen@soz.unibe.ch

\begin{abstract}
Summary: As two sides of the same coin - namely that of social capital - civic engagement and social trust have been conceived of as interrelated concepts. Existing studies examine whether civic participation is causally linked to generalized trust. However, the empirical evidence remains ambiguous: partly due to multidimensional measurement and partly in response to inadequate statistical analyses. The contribution of this paper, which uses the Swiss Household Panel data set between 2002 and 2012, is to analyze the causal relationship between participation in associations and generalized trust. Dynamic Panel Models account for the reciprocity of trust and participation with lagged dependent and lagged endogenous independent variables. The positive results support a causal effect of civic participation on generalized trust and show that joiners are trusters a priori, but also that they become trusters as they join.
\end{abstract}

Keywords: Social Capital; Participation; Trust; Causal Analysis; Dynamic Panel Models

Zusammenfassung: Freiwilliges Engagement und soziales Vertrauen werden als zwei Dimensionen des Konzepts "Sozialkapital" verstanden. Inwiefern diese Dimensionen miteinander in Beziehung stehen und ob freiwilliges Engagement ursächlich für soziales Vertrauen ist, wird in der Forschung diskutiert. Die Ergebnisse sind unterschiedlich und oft sogar widersprüchlich, was teilweise auf verschiedenen Messindikatoren und teilweise auf unzulänglicher statistischer Analyse beruht. Dieser Artikel untersucht daher die kausale Beziehung zwischen Partizipation in Vereinen und generalisiertem Vertrauen. Die Kausalanalyse basiert auf den Langzeitdaten des Schweizer Haushalts-Panel der Jahre 2002 bis 2012. Mit Hilfe von Dynamischen Panelmodellen werden die Reziprozität von Partizipation und Vertrauen als auch das Vertrauensniveau der Vorjahre in der statistischen Analyse berücksichtigt. Die Resultate zeigen einen kausalen Effekt, insofern dass die Teilnahme in Vereinen das generalisierte Vertrauen erhöht. Teilnehmer haben zwar ein höheres Vertrauensniveau a priori, aber ihr Vertrauen nimmt dennoch zu, wenn sie sich engagieren.

Schlagworte: Sozialkapital, Partizipation, Vereine, Vertrauen, Kausalanalyse, Dynamische Panel Modelle

\section{Introduction}

For decades, social scientists have viewed civic engagement and social trust as interconnected concepts. According to Robert D. Putnam (2000), both are indicators of the same larger construct, namely social capital. However, the umbrella concept of social capital is widely contested (Woolcock 2010), and debate rages over how to define this idea (Bjørnskov \& Sønderskov 2013). Although many regard trust as an essential component of social capital (Knack \& Keefer 1997; Whiteley 2000), social trust and civic engagement are often conceived of as separate dimensions (Bjørnskov \& Sønderskov 2013; Deth 2003; Franzen \& Pointner 2007; Paldam 2000). It is in view of considerable disagreement and inspired by one of Putnam's arguments that "people who join are people who trust" (Putnam 1995: 666), which causally links participation and trust, that social scientists have undertaken analyses of the relationship between these two variables. Nevertheless, the causal relationship between civic engagement and social trust remains vague, both theoretically and empirically. Further work is needed in order to demonstrate with adequate statistical analysis whether civic engagement does, in fact, share a causal link with trust. At the individual level, scholars assume that the more people trust one another, the more they participate; on the other hand, the more they take part in associational activities, the more they learn to trust. This reinforcing process describes two causal directions: selection - that is "the effect of trust on civic engagement", and causation, which "refers to the socialization effect of civic engagement on trust" (Bekkers 2012: 226). While Putnam concludes that "causation flows mainly from joining to trusting" (Putnam 1995: 666), some call into question the direction of causality, and contest the relationship between voluntary participation and social trust (Bekkers 2012; Claibourn \& Martin 2000; Newton 2001). 
As the question of civic engagement and social trust remains unresolved, this paper aims to empirically disentangle this relationship and to measure the causal effect of participation on trust by applying Dynamic Panel Models to overcome statistical shortcomings in existing analyses as well as to model the endogeneity of social capital along with micro panel data. Section 1 of this paper summarizes the theoretical debates and empirical findings on participation and generalized trust. Section 2 describes the panel dataset and provides descriptive statistics for the dependent variable and the regressor of interest. Section 3 presents the general statistical models and highlights the limitations of ordinary regression approaches. As the reciprocal relationship between trust and participation is at the heart of this study, trust as a lagged dependent variable and participation as an endogenous explanatory variable are implemented in the causal analysis. The more appropriate Dynamic Panel Models, their econometrics, and the findings of this study are outlined in Section 4, which additionally offers concluding thoughts. Finally, Section 5 summarizes the main findings.

\section{Trust and Participation}

Social trust benefits individuals and society by improving life satisfaction and health (Helliwell 2003; Kawachi et al. 2008; Rose 2000; Yip et al. 2007), democracy (Maloney et al. 2008; Paxton 2002; Putnam 1993; Zmerli \& Newton 2008), and economic outcomes (Algan \& Cahuc 2013; Beugelsdijk \& Van Schaik 2005; Knack \& Keefer 1997; Westlund \& Adam 2010). Given this, it is relevant to explore the concept of trust - how it is understood and how it is measured - and to study the mechanisms that explain its formation. In particular, determining whether voluntary participation is perhaps a micro-level determinant of social trust in others is a poorly analyzed question in social capital research and is therefore at the core of this study. ${ }^{1}$

\footnotetext{
${ }^{1}$ Although research on other determinants and other types of trust such as political or institutional trust as well as their interconnection with and importance for social trust is highly acknowledged, this paper solely analyzes the causal link of participation on social trust on the micro level. However, it will put the findings into context of institutional and socio-economic factors in 4.3.
}

\subsection{Definitions and Measurements of Trust}

Generally, social trust is understood as, "some sort of belief in the goodwill of the other" (Seligman 2000: 43), or as "faith in people [that] is treated as a generalized attitude" (Rosenberg 1956: 695). More precisely, it is defined as "the psychological state comprising the intention to accept vulnerability based upon positive expectations of the intentions or behaviour of another." (Rousseau et al. 1998, as cited in Lyon et al. 2012: 2) Although definitions of trust are ambiguous, they share the common understanding that social trust is associated with at least a dyad of actors: one of whom places faith, belief, or goodwill in the other. Researchers discuss whether these terms refer to a specific person like a neighbor, a friend, or an acquaintance from the community or whether they are more general like "someone you meet for the first time" or "most people" (Delhey et al. 2011; Freitag \& Bauer 2013; Nannestad 2008; Reeskens 2013; Torpe \& Lolle 2011). Despite the fact that social trust can be seen as a single continuum (Zmerli \& Newton 2011: 77), most researchers agree that trust is a multidimensional concept and is distinguished in at least two ways: generalized and particularized trust (cf. among others Stolle 2002; Uslaner 2002). ${ }^{2}$ These types of trust are intimately connected with explanations of how trust emerges (Freitag \& Traunmüller 2009; Torpe \& Lolle 2011; Uslaner 2002): Generalized trust is based on inherent personal predispositions or acquired in early childhood and provides a mind map with which to judge the trustworthiness of people we do not know. Because we do not have past experiences with strangers, there is no basis on which to predict behavior. Hence, we access a more general conceptual framework on the trustworthiness of unknown people and how to interact with them. Generalized trust is thus a tool for general social interaction. Particularized trust, on the other hand, refers to trust in people we know and is learned from our experiences of others' trustworthiness during socialization in adolescence and adulthood. Particularized trust is constantly updated by means of social contact and daily experience with people known to us. Conditional on these experiences, we form a "trust mindset" for how to interact with specific persons

\footnotetext{
2 Both types exist in the literature under different terminology. Yamagishi and Yamagishi (1994) propose the terms general and knowledge-based trust, Whiteley (2000) and Putnam (2000) distinguish between thick and thin trust, and Uslaner (2002) introduces strategic and moralistic trust.
} 
like family members, friends, neighbors, and people we meet in familiar contexts such as associations, church, political parties, and schools.

The extensive body of literature on how to define and measure trust reflects the complexity of the topic (e. g. Hartmann \& Offe 2001). While trust is analyzed using diverse approaches such as experimental studies and comparative research, the most common method by which trust is measured is the survey question: "Generally speaking, would you say that most people can be trusted, or that you can't be too careful in dealing with people?" This question is known as the "standard measure of social trust" (Torpe \& Lolle 2011: 482) and was first used by Rosenberg (1956) in his "faith-in-people" index. The most popular examples of comparative research surveys that use this question are the World Value Survey (WVS) and the General Social Survey (GSS). These surveys use the standard generalized trust question with a dichotomous response scale in which respondents can choose between "most people can be trusted" and "can't be too careful." 3 Although this question is widely used, researchers discuss its validity and wording (Glaeser et al. 2000; Hardin 2006; Nannestad 2008; Westlund \& Adam 2010). Delhey et al. (2011), for example, investigate how respondents understand this question. Their comparative analysis has found that the circle of individuals associated with "most people" varies significantly across countries and that these cross-country comparisons of trust levels benefit from a radius-adjusted trust score. Similarly, Sturgis and Smith (2010) analyze the frames of reference of this standard measure and reveal an ambiguity in perceptions as to whether this question refers exclusively to people we do not know. Contrary to this expectation, more than a quarter of all respondents associate the term "most people" with individuals they know personally. The validity of the standard measure is also questioned by Torpe and Lolle (2011), who conclude that comparisons of trust levels between countries, particularly between Asia and Africa, on the one hand, and the Western world, on the other, are inappropriate. Instead, they recommend using a new indicator of

\footnotetext{
${ }^{3}$ Besides the WVS and the GSS, the European Value Study (EVS) and the British Household Panel Study (BHPS), to name the most popular, have also implemented a standard binary measure of trust. However, the International Social Survey Programme (ISSP), for example, asks the same standard question but provides a five-point answer scale. Even more answer categories are available in the European Social Survey (ESS), which uses an eleven-point scale.
}

surveyed interpersonal trust: "Trust in people one is meeting for the first time." In addition to these survey-based analyses, experimental studies test the correlation between answers to the standard trust question as well as the proposer's and responder's behavior as part of a trust game. Overall, experimental studies show contradictory results (e. g. Bellemare \& Kröger 2007; Fehr et al. 2002). On one hand, trust measured by the standard question correlates with the sender's behavior and therefore measures trust (Johnson \& Mislin 2012); on the other hand, the standard question is a better indication of people's trustworthiness as measured by the amount of money returned by the receiver (Ermisch et al. 2009; Glaeser et al. 2000; Sapienza et al. 2013). Despite criticism of experimental and comparative studies, the standard question works well in national contexts, especially in Switzerland (Torpe \& Lolle 2011), where trust in most people captured by the standard phrase measures generalized trust (Delhey et al. 2011). Empirical evidence, such as think-aloud protocols, analysis of panel survey, and test-retests, suggest that it is a valid measure of trust (Nannestad 2008; Uslaner 2002, 2008). In sum, the standard survey question "may still be the best way to measure trust" (Uslaner 2012: 80).

\subsection{Empirical Studies on Trust and Participation}

Beyond on-going discussions of the definition and measurement of trust, it is important to understand how trust emerges, as it is an approved indicator of societal stability: Trust overcomes uncertainty and missing information in social interactions and therefore indicates a predisposition to cooperation (Coleman 1990); cooperation itself contributes to a stable and working society (Putnam 1993). Explanations of how trust is affected are numerous and refer either to community/macro or individual/micro characteristics. Comparative studies note that institutional and societal factors like the quality of government, political institutions, income equality, cultural values, ethnic heterogeneity, and religious diversity are determinants of trust on a macro level (Bjørnskov 2006; Delhey \& Newton 2003, 2005; Freitag 2006; Freitag \& Bühlmann 2009; Torpe \& Lolle 2011). Within these factors, the political-institutional determinants are of particular interest, as they are considered significant conditions which facilitate trust (Freitag \& Bühlmann 2009; Neller 2008; Rothstein \& Stolle 2008; Stolle 2003). The existence and perception of institutions with the characteristics enumerated in the following create a protected space where individuals can develop so- 
cial trust: First, institutions and political elites have to be perceived as stable, just, inclusive, and incorrupt, so that people are willing to trust each other. Second, institutions can create an atmosphere of trust in society by means of various incentives and sanctions. Third, the institutions of society are an environment in which citizens are socialized and learn to trust and be trustworthy. This institutioncentered approach thus presents mechanisms that demostrate how contextual determinants affect individual-level social trust.

At the micro-level, demographic variables such as education, income, gender, race, age, and place of residence are associated with trust formation (Alesina \& La Ferrara 2002; Curtis et al. 2001; Freitag 2003b; Mewes 2014; Valdivieso \& Villena-Roldan 2014). Even biological factors like genetic predispositions and hormonal balances can influence an individual's trust level (Kosfeld et al. 2005; Sturgis et al. 2010). In addition, the "society-centered approach" (Rothstein \& Stolle 2008: 442) attempts to explain variation in trust levels by experiences with other people: Social contacts can take place with regular interactions in different settings, but they are often associated with activities in voluntary associations. ${ }^{4}$ Generally, the underlying idea that socialization in groups and civic associations shape participants' norms, values, and opinions is not new. Almost two centuries ago Tocqueville (2002 [1835]) described the mind-building impact of civic associations: "Feelings and opinions are recruited, the heart is enlarged, and the human mind is developed by no other means than by the reciprocal influence of men upon each other [...] this can only be accomplished by associations." (ibid.: 583) Putnam $(1993,2000)$ also promotes this idea in his well-known studies and relates them directly to trust: "The more we connect with other people, the more we trust them, and vice versa [...] social trust and civic engagement are strongly correlated." (Putnam 1995: 665)

Although the theoretical foundation of this argumentation is rather weak in the literature, there have been attempts to explain why voluntary activity affects trust. Mewes (2014) and Bekkers (2012), for instance, propose hypotheses about how civic

\footnotetext{
${ }^{4}$ Since experiences with others which influence individuals' trust level take place in civic organisations, this perspective is also called the "civic society explanation" (Nannestad 2008: 422), the "group socialisation hypothesis" (Bekkers 2012: 228), the "Tocqueville model" (Freitag 2003a: 945), or the "voluntary organisation theory" (Delhey \& Newton 2003: 101).
}

engagement establishes trust in individuals. Bekkers (2012) describes the group socialization hypothesis, which indicates the positive effect of participation on trust. In groups such as voluntary associations, members learn values and attitudes from their coparticipants. Participation - and hence, socialization - in civic associations instigate an alignment of the new member's trust level with the average trust level of all the co-members. Mewes (2014) relates the intergroup contact theory and the affect theory of social exchange to the formation of generalized trust: According to the former, interaction with any outgroup is seen as positive in promoting tolerance and trust; the latter highlights exchange with others within an association - as they come together and pursue a joint goal - and this facilitates relationships among dissimilar people, which in turn promotes a commitment and fosters trust (Mewes 2014: 375).

In contrast, several approaches question the claim that trust is social glue that can be acquired and then fostered in associations. For instance, the stability hypothesis describes why voluntary activity does not promote trust (Bekkers 2012). Based on Uslaner's (2002) argument, this hypothesis notes that trust correlates with basic personality traits, which remain stable throughout one's life. Consequently, trust is also stable over time and is not learned in or influenced by civic engagement. In addition, the contextual diversity hypothesis as well as the group socialization perspective have sparked debate. Although both, in principle, claim a positive effect of trust, empirical researchers have contested this influence. First, the contextual diversity hypothesis proposes that diversity in groups can stimulate trust in strangers because participants are encouraged to overcome inhibitions and to learn tolerance, but points out that empirically confirmed ethical or religious heterogeneity are related to lower levels of trust (see also Delhey \& Newton 2005; Putnam 2007); hence, individuals with lower trust levels may avoid heterogeneous groups (Bekkers 2012). Second, researchers question the spillover mechanism along with the group socialization perspective (cf. among others Nannestad 2008: 422f; Freitag \& Traunmüller 2009). The argument maintains that trust, as well as norms and values, are learned via regular social interaction in associations. These internalized beliefs and attitudes are then transferred into other domains of social life. However, these spillover-mechanisms are neither sufficiently theorized nor empirically validated. Third, within the framework of the group socialization hypothesis, not all parameters of associations 
are linked with higher trust in equally strong ways. One perspective states that trust is only learned if experiences with others take place in bridging associations where dissimilar people meet; another argues that different lengths or types of memberships contribute differently to the learning of trust (Paxton 2007; Stolle 2001). Finally, researchers challenge the importance of civic associations for trust, in general, given that individuals spend more time with family, friends, and even coworkers than within associations (Newton 2001: 207), and also that the nature of civic life has shifted from face-toface interactions to check-book based memberships (Kriesi \& Baglioni 2003; Skocpol 2003).

Without a consensus definition or an explicit theory that combines micro- and macro-level determinants (Rothstein \& Stolle 2008: 443; Woolcock 2010), the literature also presents conflicting empirical results on the relationship between participation in voluntary associations and generalized trust. Some studies find positive relationships (Freitag \& Bühlmann 2009; Paxton 2007; Putnam 1993, 2000; Welch et al. 2007), while many researchers suggest that participation is not (or is only weakly) associated with trust (Delhey \& Newton 2003, 2005; Jennings \& Stoker 2004; Letki 2006; Stolle 2002; Stolle \& Hooghe 2003; Whiteley 1999). Of particular relevance, Brehm and Rahn (1997) study the reciprocal relationship of civic engagement and interpersonal trust using GSS data within a twostage-least-squares framework and find that the relationship flows from participation to trust. Conversely, Sønderskov (2011) analyzes the WVS and finds that generalized social trust increases membership in groups, although this relation is found only for associations producing public goods. On the other hand, Valdivieso and Villena-Rodan (2014) indicate the same causal direction and conclude that there is a negative effect of trust on participation in different kinds of social organizations. Given these diverse empirical findings, the direction of causality between civic engagement in associations and generalized trust is far from clear and is most probably reciprocal (Putnam 2000; Newton 2001: 207).

In this vein, different indicators and measurements of civic engagement like membership, participation, or volunteering further obscure empirical analyses. As the socialization hypothesis suggests, individuals must interact and meet face-to-face in a club or voluntary group in order to internalize social norms and learn how to trust and be trustworthy. Hence, the question of whether an individual is a member in an association is not sufficient to qualify as an in- dicator of the socialization process because interaction cannot be assumed, whereas the question of volunteering is not necessary to study in order to assume interaction. With this in mind, the empirical relationship between membership or volunteering and trust is weak. Bekkers (2012) using a Dutch panel study cannot show that changes in volunteering are associated with changes in generalized social trust and concludes that higher trust among volunteers is the result of selective attrition. Similarly, Ingen and Bekkers (2013) analyze the same dataset used in this work and additional international surveys to establish whether membership or volunteering (but not participating) enhance social trust. They find no (or only weak) relations in their models. That said, the individual's participation status is sufficient to analyze the underlying hypothesis that socialization in voluntary groups fosters trust because interaction among participants can be assumed. For instance, Claibourn and Martin (2000) cannot support the causal relationship from trust to group membership, but provide partial evidence that participation encourages interpersonal trust using panel data from Michigan. Despite these methodological pitfalls, the studies cited attempt to disentangle the reinforcing and coherent concept of participation and trust (Putnam 2000: 137) by approaching the question of causality using panel data analysis. Micro-level panel data monitors the same individuals over time thus allowing for an inter-temporal comparison which facilitates an estimate of the effect that a change in a variable has on the outcome. Panel data is preferable to cross-sectional and time-series studies because they help: (1) to control for individual (unobserved) heterogeneity of time-invariant effects and (2) to study dynamic processes (Baltagi 2013). Hence, if experiments are difficult to realize, as they are in this context, where the variable "voluntary participation" has to be systematically manipulated to estimate the effect on trust, panel data analysis is "the preeminent form of social research" (Halaby 2004: 507).

The studies cited analyze panel data to measure the inter-temporal trust change initiated by civic engagement. However, none of these studies account for the persistent character of trust; nor do they simultaneously model an endogenous relationship in their statistical analyses. Particularly, the endogeneity of civic engagement and trust is hardly considered in empirical social capital studies. This paper advances social capital research by applying both longitudinal panel data analysis and appropriate dynamic regression models which account for the 
reciprocal relationship of participation and trust with endogenous variables. Moreover, this analysis offers further substantive considerations: Compared to other studies that focus on membership or volunteering in civic organizations and their effect on trust, this paper investigates the question of participation in associations as the independent variable. Analyzing the effect of participation in groups on generalized trust is sufficient and appropriate, as one can infer interaction from participation and therefore assume socialization in an association. Thus, this paper tests the following hypothesis:

If an individual participates in voluntary associations, the individual's level of generalized trust in people increases.

\section{Data and Descriptive Statistics}

The longitudinal panel analysis employed in this study is based on the Swiss Household Panel (SHP) "Living in Switzerland Panel Survey". The SHP is an annual CATI survey, which is representative of the Swiss population in private households. In 1999, 7,799 individuals living in 5,074 participating households were interviewed for the first time. In 2012, 5,032 persons in 2,968 households completed the interview; however, only $22 \%$ responded in all eleven waves. Since the first wave, the independent variable of interest "participation in clubs or groups" has been monitored annually, whereas the question about "general trust in people" as the dependent variable, was implemented in 2002. Consequently, this paper examines respondents of the first sample (SHP_I) over a period of eleven waves, starting in the year 2002, when the dependent variable was first surveyed. Compared to the German Socio-Economic Panel Survey (GSOEP), for instance, the SHP queries both variables of interest annually. The SHP generally receives high response rates (between $81 \%$ and $89 \%$ ) and is an outstanding data source with which to analyze the relationship between the social capital dimensions of civic participation and of trust because it has collected data on the questions of interest every year for more than a decade. As in other panel studies, Voorpostel (2010) identifies attrition patterns in the SHP with regard to both demographics and social involvement variables. Although they are seemigly mild, this study follows the general principle that, in order to get more reliable results, incomplete response sets will be included. Moreover, since less civically-engaged respondents as well as those with lower trust tend to drop out more easily or are less likely to respond (Abraham et al. 2009), the effect of participation on trust is likely to be harder to determine or may be underestimated (Ingen \& Bekkers 2013: 15). Nevertheless, the representative sample from the SHP is exemplary in its quality and repeated number of measures. As a result it provides the optimal database for analysis of civic engagement and generalized trust, allowing the question of endogeneity and causal inference to be properly addressed.

Perceived generalized trust in people, as the dependent variable, is measured with the standard question: "Would you say that most people can be trusted or that you can't be too careful in dealing with people?" It is measured on an eleven-point scale, ranging from "can't be too careful" $(=0)$ to "most people can be trusted" $(=10)$. Zmerli and Newton (2008) argue that a rating scale with eleven points provides more reliable results than the dichotomized response scale of generalized trust used in the original question by Rosenberg. Uslaner (2012) highlights the problem of "clumping" that comes with the eleven-point scale, which is the "tendency of people to respond to questions with multiple alternatives by 'clumping' their answers around the mean - at values 4,5 , or 6 of the 11point scale." (ibid.: 77) Despite this criticism the SHP poses the question about generalized trust on an eleven-point response scale, from 2002 onwards, as does the European Social Survey. The key explanatory variable is the participation status in voluntary associations, asked with the question: "Do you take part in clubs' or other groups' activities, religious groups included?" (See: Online Appendix on www.zfs-online.org for details on operationalization.) The question is coded as a dummy variable with Yes $=1$ or No $=0$. Compared to other survey questions, the answers contain more information than simply measuring membership, but less than asking whether the respondent has volunteered. Unfortunately, the SHP does not ask how often or how long, in what type of association, or at what age participants began to take part in associational activities. Hence, the SHP measurement of civic engagement is only a rough indicator of the individual's socialization in voluntary groups.

In the SHP dataset the average level of generalized trust is 6.37 points on the eleven-point scale and increases between 2002 and 2005; after that it remains constant until 2012 (see Table 1 and Figure 1). Related to the explanatory variable, $56 \%$ of the Swiss population take part in clubs' or groups' activities on average. Trust systematically differs between respondents who participate in clubs or other groups and those who do not. The overall 
means of trust between participants and non-participants are significantly different (6.60 vs. 5.05, Diff $=.55, \mathrm{t}=21.71, \mathrm{p}<.000)$. Individuals with high trust are more likely to participate in voluntary associations than people with low trust. The difference between participants and non-partici- pants can either be caused by self-selection (trusters are more likely to join groups) or by causation (participation increases trust levels). Multivariate statistical analysis may be employed to estimate and quantify the causal effect of participation on trust, if any (see Section 4).

Table 1: Statistics of the variable "General trust in people"

\begin{tabular}{llllllllllll}
\hline Year of survey & 2002 & 2003 & 2004 & 2005 & 2006 & 2007 & 2008 & 2009 & 2010 & 2011 & 2012 \\
\hline Mean & 5.82 & 5.94 & 6.29 & 6.47 & 6.45 & 6.49 & 6.47 & 6.51 & 6.48 & 6.49 & 6.50 \\
Standard deviation & 2.39 & 2.33 & 2.21 & 2.16 & 2.11 & 2.10 & 2.17 & 2.06 & 2.10 & 2.02 & 2.02 \\
N Respondents (Trust) & 2461 & 2496 & 2457 & 2468 & 2615 & 2694 & 2743 & 2793 & 2920 & 2990 & 2985 \\
\multirow{2}{*}{ Mean* ${ }^{*}$ Non-Participants } & 5.53 & 5.69 & 5.90 & 6.20 & 6.12 & 6.17 & 6.13 & 6.18 & 6.15 & 6.14 & 6.23 \\
& 6.03 & 6.12 & 6.56 & 6.66 & 6.68 & 6.72 & 6.72 & 6.76 & 6.73 & 6.77 & 6.73 \\
\hline
\end{tabular}

Pearson's correlation coefficients $(\bar{r}=.62)$

\begin{tabular}{lllllllllllllll}
2002 & 1 & & & & & & & & & & \\
2003 & 0.55 & 1 & & & & & & & & & \\
2004 & 0.51 & 0.53 & 1 & & & & & & & & \\
2005 & 0.52 & 0.55 & 0.60 & 1 & & & & & & & \\
2006 & 0.54 & 0.54 & 0.58 & 0.60 & 1 & & & & & & \\
2007 & 0.53 & 0.56 & 0.59 & 0.62 & 0.63 & 1 & & & & & \\
2008 & 0.51 & 0.51 & 0.58 & 0.60 & 0.61 & 0.63 & 1 & & & & \\
2009 & 0.51 & 0.55 & 0.59 & 0.61 & 0.62 & 0.62 & 0.65 & 1 & & & \\
2010 & 0.53 & 0.52 & 0.60 & 0.61 & 0.64 & 0.67 & 0.64 & 0.68 & 1 & & \\
2011 & 0.50 & 0.51 & 0.57 & 0.58 & 0.60 & 0.61 & 0.62 & 0.64 & 0.68 & 1 & \\
2012 & 0.49 & 0.50 & 0.57 & 0.57 & 0.60 & 0.62 & 0.60 & 0.63 & 0.65 & 0.67 & 1 \\
\hline
\end{tabular}

Notes: Swiss Household Panel 2002-2012; * all mean differences are significant at $p<0.001$

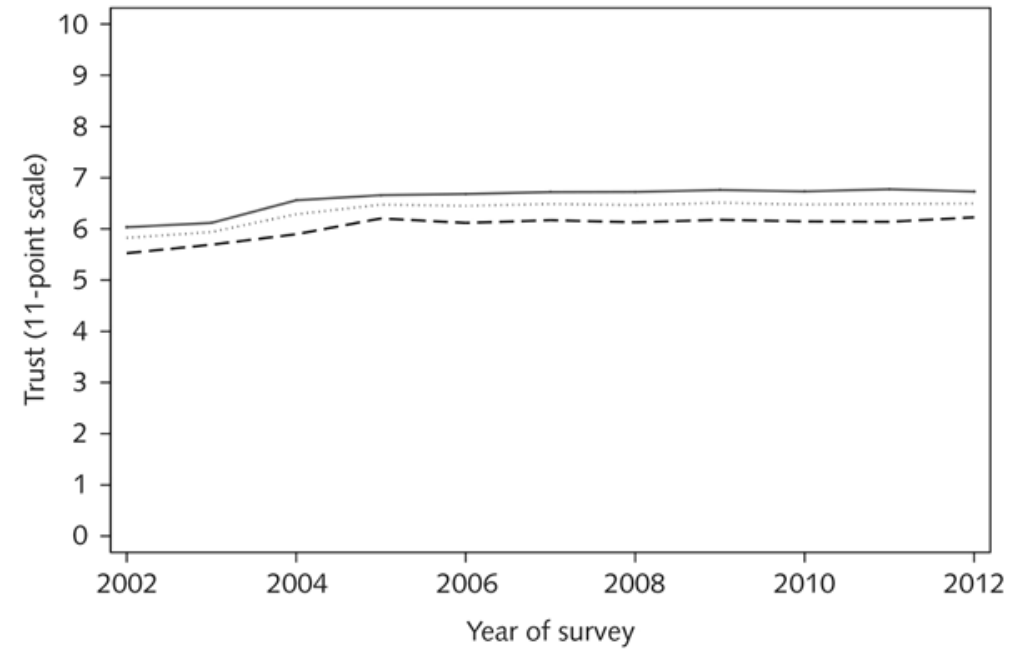

Participants -----Non-participants
Figure 1: General trust in people by year and participation status

Note: Swiss Household Panel 20022012 

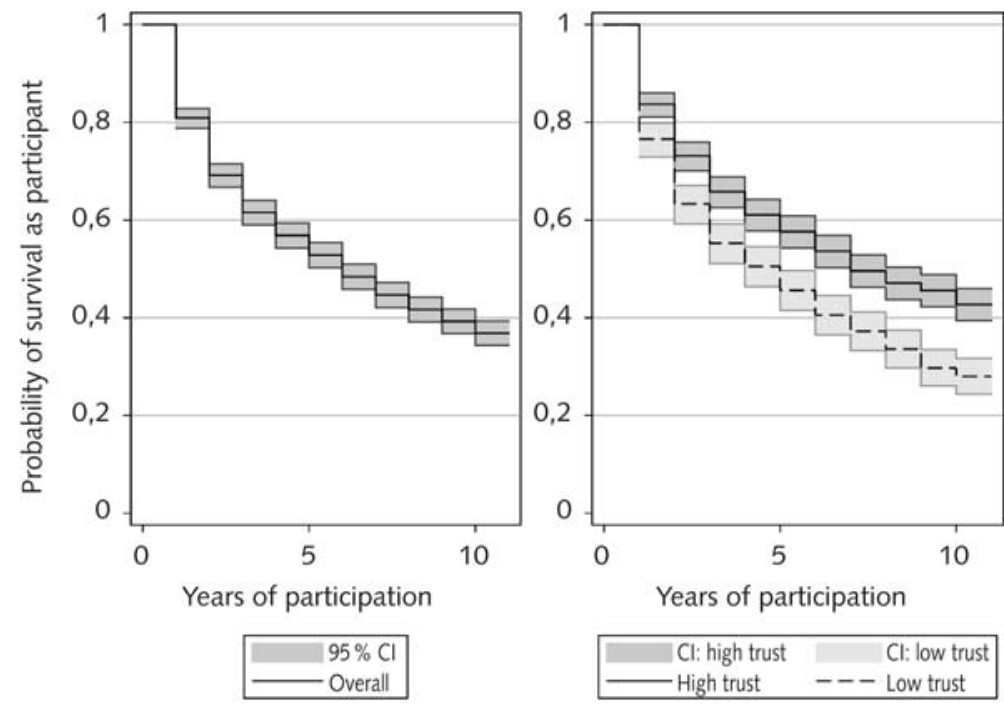

Figure 2: Survival probability of participants

Note: Swiss Household Panel 20022012
The probability of sustaining participation in clubs or other groups is illustrated in Figure 2. The graph on the left shows the overall probability of survival as a participant. After the first year, roughly $19 \%$ of participants cease to attend voluntary groups. The dropout rate decelerates after this. At the end of eleven years, $36.8 \%$ of the participants remain in associations, the so-called sustainers. The right side of Figure 2 separately illustrates the probability of remaining in the group for participants who have low trust (lower than the mean) and for participants with high trust. People who are less trusting are more likely to quit than those with high trust. They leave voluntary groups faster and more often than high-trusting participants. After eleven years, $72 \%$ of those with a low degree of trust ceased participation, whereas only $57 \%$ of the individuals with a high degree of trust quit voluntary groups. These findings support the selection hypothesis: selection in the sense that trusters are more likely to survive as participants in associations. Nevertheless, although trust seems to be a precondition for participation (Ingen \& Bekkers 2013), causation, i. e. the generation of trust via participation, can still be a mechanism that additionally affects the positive relationship between participation and trust, although it may be more difficult to detect.

\section{General Statistical Model}

This section derives a statistical model in order to examine whether participation in clubs or other groups $(P A R T)$ increases generalized trust in people
(TRUST). Later, the model is transferred to an appropriate estimation method, viz. Dynamic Panel Model Regression. As the model is supposed to contain the reciprocal relationship of participation and trust as well as the persistence of the dependent variable, the equation is built on the following general statistical model, which is later modified:

$y_{i, t}=\beta_{1}+\gamma y_{i, t-1}+\sum_{j=1}^{J} \beta_{j} x_{j i, t}+u_{i}+e_{i, t}$

where $y_{i, t-1}$ is a lagged dependent variable, $x_{j i, t}$ stands for multiple $(j>1)$ explanatory variables (at this point it has not been determined whether they are endogenous, predetermined, or strictly exogenous), $u_{i}$ is an unobserved individual-specific, timeconstant effect (fixed effect), and $e_{i, t}$ reflects the random disturbance term. Under the assumption that the relationship between the dependent variable and the regressors is adequately modeled, the error component of the regression equation can be summarized as: $e_{i, t}^{*}=u_{i}+e_{i, t}$ (Wawro 2002). As a first step, the general model in Eq. (1) is modified so that the lagged dependent variable is now firstand second-order autoregressive and thus models the persistence and correlation between current and past levels of trust (see Eq. (2)). Since trust is considered a reinforcing, endogenous, and even stable characteristic, trust at time $t$ is influenced by the attitude of previous times $t-k$. Statistically, the lagged dependent variables express the variance in the current trust level, which could have been otherwise (erroneously) assigned to other regressors. Second, a lagged explanatory variable $P A R T_{i, t-1}$ is implemented to test whether the previous year of partici- 
pation, in addition to current participation statuses, influences present trust levels. According to the socialization hypothesis, trust can be learned and fostered in associations where it is likely that the current year and previous years of participation influence trust levels. Hence, the modified equation contains the lagged dependent variable TRUST first- and second-order autoregressive $\left(\gamma_{1} T R U S T_{i, t-1}\right.$, $\gamma_{2}$ TRUST $\left._{i, t-2}\right)$, a lagged explanatory variable PART first-order autoregressive $\left(\beta_{2} P A R T_{i, t-1}\right)$ to capture the persistence of the variables, and control variables represented by $\sum_{j=1}^{J} \beta_{j} x_{j i, t}$. It is referred to as the
full model:

$$
\begin{aligned}
& \text { TRUST }_{i, t}=\beta_{1}+\gamma_{1} \text { TRUST }_{i, t-1}+\gamma_{2} \text { TRUST }_{i, t-2} \\
& +\beta_{2} \text { PART }_{i, t}+\beta_{2} \text { PART }_{i, t-1}+\sum_{j=1}^{j} \beta_{i} x_{j i, t}+u_{i}+e_{i, t}
\end{aligned}
$$

However, the inference from models with lagged dependent variables can be problematic because they are confronted with the problem that the individual time-constant effects $u_{i}$ are correlated with the dependent variable lagged once $y_{i, t-1}$ (see Eq.(1)). As an example of why fixed effects are associated with $y_{i, t-1}$, one can imagine an exogenous "shock" (e. g. financial crises, wars, natural catastrophes) that has boosted or destroyed previous levels of trust. This change in trust as a response to universal societal disturbances ends up in the fixed effects of present trust levels. Hence, these fixed effects $u_{i}$, as part of the error term $e_{i, t}^{*}=u_{i}+e_{i, t}$, are in turn correlated with the regressor $y_{i, t-1}$. In other words, the current trust level $y_{i, t}$ is a function of the individual fixed effects, which are correlated with the lagged dependent variable. Hence, the regression assumption of uncorrelated error terms is violated. The endogeneity bias would be smaller if the number of time periods $t$ was high. But in samples with limited numbers of time periods, the bias can inflate the OLS regression estimate $\gamma$. Judson \& Owen (1999) as well as Nickell (1981) demonstrate that the bias is severe in samples where $t$ is small. Although Keele \& Kelly (2006) show that it may be appropriate to use OLS with a lagged dependent variable under certain circumstances (ibid: p. 187), they conclude that if the model residuals are strongly autocorrelated, the lagged dependent variable causes severe bias (see also Bond 2002). To test for autocorrelated error terms, an Arellano-Bond ( $\mathrm{AB}$ ) test for autocorrelation was conducted (Arellano \& Bond 1991; Roodman 2009), which reveals strongly correlated residuals in the linear models. Therefore, OLS and FE estimates are biased and inconsistent (Wawro 2002: 29) and interpretations should be judged cautiously. As a result, to overcome the disadvantages of OLS and FE in a dynamic context, this study applies Dynamic Panel Model Regression.

\section{Dynamic Panel Model Analysis}

The following section tests this paper's hypothesis using SHP data from the period 2002-2012. Since this study analyzes a high number of individuals at only eleven time periods with lagged dependent and endogenous explanatory variables, Dynamic Panel Models (DPM) provides the most adequate framework. This approach attempts to solve the previously discussed problem of endogenous dependent variables in two steps. First, DPM takes the first difference of the general regression equation Eq. (1). From this, DPM eliminates the constant term and, more importantly, the potential bias created by unobserved, individual-specific effects. The first-difference yields the equation:

$\Delta y_{i, t}=\gamma \Delta y_{i, t-1}+\beta \Delta x_{i, t}+\Delta e_{i, t}$

The second step is to instrument the lagged dependent variable with past levels of that variable (lagged values). This step is needed because the transformation in the first step leaves $y_{i, t-1}$ of the term $\Delta y_{i, t-1}$ $\left(=y_{i, t}-y_{i, t-1}\right)$ in Eq. (3) correlated with $e_{i, t-1}$ embedded in $\Delta e_{i, t}\left(=e_{i, t}-e_{i, t-1}\right)$. The standard approach to adjust for the correlation of the lagged variable with the disturbance term is to use instrumental variable (IV) regression. Since researchers seldom have access to good external instruments, they can take advantage of the panel structure, which provides a set of internal instruments. Lagged values can be used as instruments because they should be correlated with the first differences of the righthand variable that needs to be instrumented and are uncorrelated with the errors. To use all available instruments provided by the panel data, the General Method of Moments (GMM) is applied, which allows for estimating more moment conditions than there are parameters in the model. This over-identification of parameters leads to efficient estimators (Wooldridge 2001). Arellano \& Bond (1991) instrument equations in first differences with levels of the explanatory variables, whereas Arellano \& Bover (1995) and Blundell \& Bond (1998) extend this idea, using lagged differences as instruments for equations in levels. Roodman (2009: 114) notes that "past changes may indeed be more predictive of current levels than past levels are of current changes, so that the new instruments are more relevant.” The Blundell \& Bond approach 
is known as System-GMM (S-GMM), which works well when the number of observations is large while the number of time periods for which data is available is small, as it is the case with SHP data.

\subsection{Empirical Findings}

To summarize, the basic idea of DPM is to take the first difference in order to eliminate the constant term and the unobserved, individual-specific effects of the equation; and, as a second step, to instrument the lagged dependent (and independent) variables with past levels of these variables provided by the panel data. The dynamic fixed-effects panel model from Eq. (2) is estimated. The regression controls for the yearly total gross income (logarithmized), years of education, whether a person's work status is active, whether a person is divorced, is feeling healthy, or has children. When analyzing civic participation and trust, much of the literature notes the importance of these control variables. As is generally recommended, time dummies are included in all models in order to capture the overall level and change in trust as well as cross-section correlation. In addition, the assumption is varied according to whether the social capital indicator "participation in groups" is exogenous or endogenous, meaning that it is either correlated with the lagged level of trust or not. The endogeneity assumption reflects the reciprocal relationship that civic engagement and trust are "as tangled as welltossed spaghetti" (Putnam 2000: 137). In the case that the variable is assumed to be endogenous, the study applies the instrumental variable approach, as described in the GMM framework. Owing to the fact that exogenous instruments are not available, the study takes advantage of the useful characteristic of panel data and uses lagged variables, secondorder autoregressive and higher as instruments for the endogenous regressor PART.

The results of the S-GMM Dynamic Panel Models are reported in Table 2. If causation, i. e. the generation of trust via participation, is the mechanism at work, a change in trust should be observable in response to a change in participation status; and, indeed, whether an individual participates in clubs or other groups has a statistically positive impact on their general level of trust in people. However, if the variable "participation in groups" is assumed to be endogenous rather than exogenous, the relationship drops considerably, but remains positive and significant. Compared to the null model and the full model 1 (see Table 2), it is the previous year, rather than current participation status, which is associated with higher trust levels. If an individual has been socialized in a group for the past year, the current additional year does not contribute to the trust building process. If an individual started participating in clubs or other groups in the previous year, the trust level rises by .15 on average, all else held constant. Moreover, the results indicate that individuals who have a higher level of education, better health, and who have children tend to trust more. Whether the control variables are assumed to be exogenous, predetermined, or endogenous does not affect the significant relationship between participation and trust.

\subsection{Robustness Tests}

In light of the statistical reliability of previous DPM regression results, it is important to consult specification checks and test the requirements of the models. Generally, DPM assumes no serially correlated error terms but valid instruments. First, the test for serial correlation of the residuals by Arellano \& Bond (1991) analyzes whether the errors $e_{i, t}$ across time periods are correlated. This is important because the consistency of the regression estimates depends on the assumption that the first-differenced residuals $\Delta e_{i, t}=e_{i, t}-e_{i, t-1}$ should be uncorrelated with $y_{i, t-2}$, so that $y_{i, t-2}$ satisfies the condition as a valid instrument (Wawro 2002). ${ }^{5}$ The ArellanoBond test for autocorrelated error terms is reported in Table 3. It shows insignificant test results, meaning that the second lags are valid instruments for the endogenous variables. Since efficient and consistent estimates of DPM - particularly within the GMM approach - are conditioned on good instrumental variables, the validity of the instruments and the associated requirements can also be tested with a second specification test. In a two-step GMM framework with robust standard errors, Hansen's J-statistic (Baum et al. 2003; Hansen 1982 ) is appropriate to test whether all instruments are valid against the alternative of whether any subset of the instruments are invalid. As the null hypothesis for joint validity is not rejected, the second lags of the current values of the variables seem to be valid instruments. Furthermore, the "Differencein-Hansen" or C-test (Baum et al. 2003; Roodman

\footnotetext{
${ }^{5}$ If the errors are correlated across time periods, the first differenced error term includes $e_{i, t-2}$ and is therefore correlated with $y_{i, t-2}$. Hence, the twice-lagged variable is no longer an adequate instrument. Nevertheless, $y_{i, t-3}$ and deeper lags remain valid instruments.
} 
Table 2: Dynamic Panel Models of trust and participation status

\begin{tabular}{|c|c|c|c|c|c|}
\hline & Null model & $\begin{array}{c}\text { Full model } \\
1\end{array}$ & $\begin{array}{c}\text { Full model } \\
2\end{array}$ & $\begin{array}{c}\text { Full model } \\
3\end{array}$ & $\begin{array}{c}\text { Full model } \\
4\end{array}$ \\
\hline & \multicolumn{5}{|c|}{ DV: Generalized trust in people } \\
\hline \multirow[t]{2}{*}{ L1.General trust in people } & $0.079^{* * *}$ & $0.097^{* * *}$ & $0.093^{* * *}$ & $0.114^{* * *}$ & $0.112^{* * *}$ \\
\hline & $(0.000)$ & $(0.000)$ & $(0.000)$ & $(0.000)$ & $(0.000)$ \\
\hline \multirow[t]{2}{*}{ L2.General trust in people } & 0.010 & 0.019 & 0.020 & $0.039^{* *}$ & $0.040^{* *}$ \\
\hline & $(0.426)$ & $(0.185)$ & $(0.168)$ & $(0.004)$ & $(0.004)$ \\
\hline \multirow[t]{2}{*}{ Participation in groups } & $0.277^{* * *}$ & $0.226^{* * *}$ & -0.030 & -0.012 & -0.075 \\
\hline & $(0.000)$ & $(0.000)$ & $(0.914)$ & $(0.947)$ & $(0.685)$ \\
\hline \multirow[t]{2}{*}{ L1.Participation in groups } & $0.278^{* * *}$ & $0.243^{* * *}$ & $0.150^{*}$ & $0.148^{* *}$ & $0.149^{* *}$ \\
\hline & $(0.000)$ & $(0.000)$ & $(0.019)$ & $(0.005)$ & $(0.005)$ \\
\hline \multicolumn{6}{|l|}{ Control variables } \\
\hline \multirow[t]{2}{*}{ Yearly income (In) } & & -0.008 & -0.008 & -0.010 & 0.009 \\
\hline & & $(0.709)$ & $(0.714)$ & $(0.785)$ & $(0.884)$ \\
\hline \multirow[t]{2}{*}{ Work Status } & & 0.013 & 0.041 & $-0.158^{*}$ & $-0.377^{*}$ \\
\hline & & $(0.777)$ & $(0.394)$ & $(0.017)$ & $(0.011)$ \\
\hline \multirow[t]{2}{*}{ Education in years } & & $0.090^{* * *}$ & $0.092^{* * *}$ & 0.039 & 0.029 \\
\hline & & $(0.000)$ & $(0.000)$ & $(0.069)$ & $(0.307)$ \\
\hline \multirow[t]{2}{*}{ Divorce } & & -0.029 & -0.090 & 0.276 & -0.122 \\
\hline & & $(0.755)$ & $(0.354)$ & $(0.196)$ & $(0.562)$ \\
\hline \multirow[t]{2}{*}{ Health } & & $0.285^{* * *}$ & $0.301^{* * *}$ & $0.127^{* *}$ & 0.221 \\
\hline & & $(0.000)$ & $(0.000)$ & $(0.009)$ & $(0.303)$ \\
\hline \multirow[t]{2}{*}{ Children } & & $0.082^{*}$ & $0.084^{*}$ & 0.039 & 0.222 \\
\hline & & $(0.039)$ & $(0.043)$ & $(0.431)$ & $(0.089)$ \\
\hline \multirow[t]{2}{*}{ Constant } & $5.441^{* * *}$ & $4.050^{* * *}$ & $4.231^{* * *}$ & $5.010^{* * *}$ & $4.955^{* * *}$ \\
\hline & $(0.000)$ & $(0.000)$ & $(0.000)$ & $(0.000)$ & $(0.000)$ \\
\hline N Observations & 22174 & 19871 & 19871 & 19871 & 19871 \\
\hline N Groups & 3006 & 2936 & 2936 & 2936 & 2936 \\
\hline AB-test for $A R(2)$ ( $p$-value) & .989 & .508 & .447 & .178 & .136 \\
\hline Hansen's J test ( $p$-value) & .058 & .528 & .167 & .235 & .306 \\
\hline$N$ Instruments & 65 & 70 & 121 & 481 & 433 \\
\hline Participation variable & exogenous & exogenous & endogenous & endogenous & endogenous \\
\hline Control variables & - & exogenous & exogenous & predetermined & endogenous \\
\hline Time dummies & yes & yes & yes & yes & yes \\
\hline
\end{tabular}

Notes: Swiss Household Panel 2002-2012; all models are two-step S-GMM regressions; $p$-values in parentheses; ${ }^{*} p<0.05,{ }^{* *} p<0.01$, *** $\mathrm{p}<0.001$; standard errors are cluster-robust Windmeijer-corrected errors.

2009), which examines whether a subset of instruments is valid, does not show significant results. As the number of instruments weakens Hansen's J-statistic, Table 2 also reports the number of instruments used in the models. Conditional on the combination of features modified in the DPM regressions, tests of specification favor different models. However, the overall inference suggests that if a person has started participating in clubs or other groups in the past year, the level of trust increases, on average, by about .15 points on the trust-scale, given that the explanatory variable "participation in groups" is assumed to be endogenous. More statistical reliability checks are outlined in the Online Appendix (see www. zfs-online.org). 
With regard to substantive robustness, modifications were conducted to test whether the positive relationship between participation and generalized trust differs for different lengths of participation or for participants with either low or high trust. First, it does not significantly contribute to the increase in trust if the lag depth is extended to two or three lags. Foremost, if the respondent participated during the previous year, the current trust level is positively affected. Secondly, the analysis was repeated separately for respondents with low and high trust. As Bekkers (2012: 230) states, "it is reasonable to expect floor- and ceiling-effects"; hence, one assumes that participants with low trust experience a greater increase in level compared to those whose trust is already high. And indeed, the causal effect of participation in groups was stronger for individuals who initially have low trust, thus supporting the ceiling-effect hypothesis.

\subsection{Interpretation and Implications}

Although the relationship between civic participation and generalized trust is considered reciprocal, taking part in association activities raises the trust one places in other people. While these analyses rely on representative Swiss survey data, the findings cannot easily be generalized to other settings. Switzerland seems to be a context that represents a fertile ground on which to generate trust in people. Hence, it may be that analyses in countries where the institutional and socio-economic context is not as solid as in Switzerland will produce different results. According to various social scientists (Bjørnskov 2006; Freitag \& Bühlmann 2009; Nannestad 2008; Rothstein \& Eek 2009), functional political institutions and governments, which are regarded as catalysts for the general trust level, are of particular interest; moreover, a sound economy and a vital civil society are crucial for facilitating trust in other people. Therefore, the relationship between civic-mindedness and trust depends heavily on context. Comparative research shows that differences in levels of trust between participants and non-participants significantly vary between countries. Thus, it is likely that macro-level determinants have greater impact on the individual trust level than socialization in associations. It seems that the interaction of country-specific circumstances in Switzerland provides the context in which civic engagement can positively influence trust. At least for Switzerland, investing in the population's civic engagement would potentially increase generalized trust.
As this study finds a positive effect on generalized trust of participation and therefore a socializationeffect in associations, it opens the field to further investigations with respect to different subcategories of variables which may facilitate an understanding of individual characteristics that mediate the positive influence of civic engagement on trust. For policy suggestions it is important to understand whether different age groups learn trust differently in associations or whether - and to what extent participation of natives compared to immigrants affects trust. Additionally, the length and intensity of participation as well as the type of civic group should usefully have been included in the SHP in order to examine their impact on the individual's trust formation. Since Putnam $(1993,2000)$ states that bridging and bonding social capital have different effects in regard to society, the type of association could help to ascertain whether bridging and/ or bonding associations foster social trust (see Sønderskov 2011). If the length of participation had been surveyed, the length of socialization in an association which positively influences individuals' trust level would have been revealed. Moreover, household characteristics can affect the chance of participation as well as the level of trust. Future research may therefore take into account contagion of behavior and attitudes among household members, as well as the effect of the composition of households. In addition, this study leaves unanswered the question as to why participation, but not volunteering, enhances trust. Ingen \& Bekkers (2013) as well as Bekkers (2012) found no effect of volunteering on trust levels; yet, the current analysis supports the positive influence of participation on trust. Future studies may want to examine the reason for the different effects of volunteering and participation. One potential factor might be that participants and volunteers systematically differ in their trust levels in the sense that volunteers trust more than participants. By virtue of ceiling-effects, for instance, one can assume that the effect on trust is only detectable among participants and not among volunteers. Finally, this study cannot test the causal mechanisms which explain how participation leads to generalized trust. The hypothesis as to whether participation only influences particularized trust, which is then generalized, or whether there is a direct link between participation and generalized trust is not empirically examined. Both types of trust have to be available in the survey, but are not present in the SHP. Future empirical investigation, guided by reasonable theoretical foundations, may want to analyze if and how particular- 
ized trust gained through associational activity may lead to generalized trust.

\section{Conclusion}

The starting point of this study was the social capital theorists' claim that civic engagement is positively and reciprocally linked to generalized trust. Although empirical findings contest this hypothesis, the theoretical argumentation of this relationship is grounded either on selection or on causation mechanisms. This work attempts to disentangle the two and to ascertain the causal effect of participation on trust using appropriate statistical models. First, bivariate analysis suggests a self-selection process insofar as individuals with high trust are more likely to sustain participation in voluntary associations. With a focus on the causal effect, multivariate analyses support the group socialization hypothesis. While previous studies applied multivariate approaches such as Ordinary Least Squares and Fixed Effect Regression, which have limitations in properly addressing the problem of endogeneity as well as neglecting the persistence of included variables, this study employs appropriate panel data analysis in order to model dynamics and endogeneity simultaneously. The applied Dynamic Panel Models account for the reciprocity of trust and civic participation with lagged dependent and independent endogenous variables. As hypothesized, the results support a causal effect of civic engagement on generalized trust and show that trust in people increases when individuals join and participate in associations. With DPM regression, however, the effect of participation on trust is small compared to ordinary regression models, but it remains positive and significant. The size of the effect can either be a result of the fact that the relationship is rather weak and/or the fact that the survey measurements of civic participation and generalized trust are both weak and therefore only show a weak correlation. However, compared to existing studies on civic engagement and trust, which use multidimensional measurements or inadequate statistical approaches, this research goes beyond former analyses by modeling the endogeneity of civic participation and trust and shows that joiners are not just trusters, but also become trusters as they join.

\section{Bibliography}

Abraham, K.G., S. Helms \& S. Presser, 2009: How Social Processes Distort Measurement: The Impact of Survey Nonresponse on Estimates of Volunteer Work in the United States. American Journal of Sociology 114: 1129-1165.

Alesina, A. \& E. La Ferrara, 2002: Who Trusts Others? Journal of Public Economics 85: 207-234.

Algan, Y. \& P. Cahuc, 2013: Trust and Growth. Annual Review of Economics 5: 521-549.

Arellano, M. \& S. Bond, 1991: Some Tests of Specification for Panel Data: Monte Carlo Evidence and an Application to Employment Equations. The Review of Economic Studies 58: 277-297.

Arellano, M. \& O. Bover, 1995: Another Look at the Instrumental Variable Estimation of Error-Components Models. Journal of Econometrics 68: 29-51.

Baltagi, B.H., 2013: Econometric Analysis of Panel Data. Chichester: Wiley.

Baum, C.F., M.E. Schaffer \& S. Stillman, 2003: Instrumental Variables and GMM: Estimation and Testing. The Stata Journal 3: 1-31.

Bekkers, R., 2012: Trust and Volunteering: Selection or Causation? Evidence from a 4 Year Panel Study. Political Behavior 34: 225-247.

Bellemare, C. \& S. Kröger, 2007: On Representative Social Capital. European Economic Review 51: 183-202.

Beugelsdijk, S. \& T. Van Schaik, 2005: Social Capital and Growth in European Regions: An Empirical Test. European Journal of Political Economy 21: 301-324.

Bjørnskov, C., 2006: Determinants of Generalized Trust: A Cross-country Comparison. Public Choice 130: 1-21.

Bjørnskov, C. \& K.M. Sønderskov, 2013: Is Social Capital a Good Concept? Social Indicators Research 114: 1225-1242.

Blundell, R. \& S. Bond, 1998: Initial Conditions and Moment Restrictions in Dynamic Panel Data Models. Journal of Econometrics 87: 115-143.

Bond, S., 2002: Dynamic Panel Data Models: A Guide to Microdata Methods and Practice. CeMMap wWorking Papers No. CWP09/02, Centre for Microdata Methods and Practice, Institute for Fiscal Studies.

Brehm, J. \& W. Rahn, 1997: Individual-Level Evidence for the Causes and Consequences of Social Capital. American Journal of Political Science 41: 999-1023.

Claibourn, M. \& P. Martin, 2000: Trusting and Joining? An Empirical Test of the Reciprocal Nature of Social Capital. Political Behavior 22: 267-291.

Coleman, J.S., 1990: Foundations of Social Theory. Cambridge: Belknap Press of Harvard University Press.

Curtis, J.E., D.E. Baer \& E.G. Grabb, 2001: Nations of Joiners: Explaining Voluntary Association Membership in Democratic Societies. American Sociological Review 66: 783-805.

Delhey, J. \& K. Newton, 2003: Who Trusts? The Origins of Social Trust in Seven Societies. European Societies 5: 93-137.

Delhey, J. \& K. Newton, 2005: Predicting Cross-National Levels of Social Trust: Global Pattern or Nordic Exceptionalism? European Sociological Review 21: 311-327. 
Delhey, J., K. Newton \& C. Welzel, 2011: How General Is Trust in "Most People"? Solving the Radius of Trust Problem. American Sociological Review 76: 786-807.

Deth, J.W.V., 2003: Measuring Social Capital: Orthodoxies and Continuing Controversies. International Journal of Social Research Methodology 6: 79-92.

Ermisch, J., D. Gambetta, H. Laurie, T. Siedler \& S.C.N. Uhrig, 2009: Measuring People's Trust. Journal of the Royal Statistical Society 172: 749-769.

Fehr, E., U. Fischbacher, B. Von Rosenbladt, J. Schupp \& G.G. Wagner, 2002: A Nation-wide Laboratory. Examining Trust and Trustworthiness by Integrating Behavioral Experiments into Representative Survey. Schmollers Jahrbuch 122: 519-542.

Franzen, A. \& S. Pointner, 2007: Sozialkapital: Konzeptualisierungen und Messungen. Pp 66-90 in: A. Franzen \& M. Freitag (eds.), Sozialkapital. Grundlagen und Anwendungen. Special Issue No. 47 of the Kölner Zeitschrift für Soziologie und Sozialpsychologie. Wiesbaden: VS.

Freitag, M., 2003a: Social Capital in (Dis)similar Democracies - The Development of Generalized Trust in Japan and Switzerland. Comparative Political Studies 36: 936-966.

Freitag, M., 2003b: Beyond Tocqueville: The Origins of Social Capital in Switzerland. European Sociological Review 19: 217-232.

Freitag, M., 2006: Bowling the State Back. in: Political Institutions and the Creation of Social Capital. European Journal of Political Research 45: 123-152.

Freitag, M. \& M. Bühlmann, 2009: Crafting Trust: The Role of Political Institutions in a Comparative Perspective. Comparative Political Studies 42: 1537-1566.

Freitag, M. \& R. Traunmüller, 2009: Spheres of Trust: An Empirical Analysis of the Foundations of Particularised and Generalised Trust. European Journal of Political Research 48: 782-803.

Freitag, M. \& P.C. Bauer, 2013: Testing for Measurement Equivalence in Surveys: Dimensions of Social Trust across Cultural Contexts. Public Opinion Quarterly 77: 24-44.

Glaeser, E.L., D.I. Laibson, J.A. Scheinkman \& C.L. Soutter, 2000: Measuring Trust. The Quarterly Journal of Economics 115: 811-846.

Halaby, C., 2004: Panel Models in Sociological Research: Theory into Practice. Annual Review of Sociology 30: 507-544.

Hansen, L.P., 1982: Large Sample Properties of Generalized Method of Moments Estimators. Econometrica 50: 1029-1054.

Hardin, R., 2006: Trust. Cambridge: Polity Press.

Hartmann, M. \& C. Offe, 2001: Vertrauen: die Grundlage des sozialen Zusammenhalts. Frankfurt: CampusVerlag.

Helliwell, J.F., 2003: How's Life? Combining Individual and National Variables to Explain Subjective WellBeing. Economic Modelling 20: 331-360.

Ingen, E.V. \& R. Bekkers, 2013: Generalized Trust Through Civic Engagement? Evidence from Five National Panel Studies. Political Psychology 36(3): 277-294.

Jennings, M.K. \& L. Stoker, 2004: Social Trust and Civic
Engagement across Time and Generations. Acta Politica 39: 342-379.

Johnson, N. \& A. Mislin, 2012: How Much Should We Trust the World Values Survey Trust Question? Economics Letters 116: 210-212.

Judson, R.A. \& A.L. Owen, 1999: Estimating Dynamic Panel Data Models: A Guide for Macroeconomists. Economics Letters 65: 9-15.

Kawachi, I., S.V. Subramanian \& D. Kim, 2008: Social Capital and Health. New York: Springer.

Keele, L. \& N.J. Kelly, 2006: Dynamic Models for Dynamic Theories: The Ins and Outs of Lagged Dependent Variables. Political Analysis 14: 186-205.

Knack, S. \& P. Keefer, 1997: Does Social Capital Have an Economic Payoff? A Cross-Country Investigation. The Quarterly Journal of Economics 112: 1251-1288.

Kosfeld, M., M. Heinrichs, P.J. Zak, U. Fischbacher \& E. Fehr, 2005: Oxytocin Increases Trust in Humans. Nature 435: 673-676.

Kriesi, H. \& S. Baglioni, 2003: Putting Local Associations into their Context. Preliminary Results from a Swiss Study of Local Associations. Swiss Political Science Review 9: 1-34.

Letki, N., 2006: Investigating the Roots of Civic Morality: Trust, Social Capital, and Institutional Performance. Political Behavior 28: 305-325

Lyon, F., G. Möllering \& M.N.K. Saunders, 2012: Introduction: the Variety of Methods for the Multi-faceted Phenomenon of Trust. P. 1-15 in: F. Lyon, G. Möllering \& M.N.K. Saunders (eds.), Handbook of Research Methods on Trust. Cheltenham: Edward Elgar.

Maloney, W.A., J.W.V. Deth \& S. Rossteutscher, 2008: Civic Orientations: Does Associational Type Matter? Political Studies 56: 261-287.

Mewes, J., 2014: Gen(d)eralized Trust: Women, Work, and Trust in Strangers. European Sociological Review 30: 373-386.

Nannestad, P., 2008: What Have We Learned about Generalized Trust, If Anything? Annual Review of Political Science 11: 413-436.

Neller, K., 2008: Explaining Social Trust: What Makes People Trust Their Fellow Citizens? Pp 103-133 in: H. Meulemann (ed.), Social Capital in Europe: Similarity of Countries and Diversity of People? Leiden: Brill.

Newton, K., 2001: Trust, Social Capital, Civil Society, and Democracy. International Political Science Review 22: 201-214.

Nickell, S., 1981: Biases in Dynamic Models with Fixed Effects. Econometrica 49: 1417-1426.

Paldam, M., 2000: Social Capital: One or Many? Definition and Measurement. Journal of Economic Surveys 14: 629-653.

Paxton, P., 2002: Social Capital and Democracy: An Interdependent Relationship. American Sociological Review 67: 254-277.

Paxton, P., 2007: Association Memberships and Generalized Trust: A Multilevel Model Across 31 Countries. Social Forces 86: 47-76.

Putnam, R.D., 1993: Making Democracy Work: Civic Traditions in Modern Italy. Princeton: Princeton University Press. 
Putnam, R.D., 1995: Tuning In, Tuning Out: The Strange Disappearance of Social Capital in America. Political Science \& Politics 28: 664-683.

Putnam, R.D., 2000: Bowling Alone. The Collapse and Revival of American Community. New York: Simon \& Schuster.

Putnam, R.D., 2007: E pluribus unum: Diversity and Community in the Twenty-first Century. The 2006 Johan Skytte Prize Lecture. Scandinavian Political Studies 30: 137-174.

Reeskens, T., 2013: But Who Are those "Most People" that Can Be Trusted? Evaluating the Radius of Trust Across 29 European Societies. Social Indicators Research 114: 703-722.

Roodman, D., 2009: How to Do xtabond2: An Introduction to Difference and System GMM in Stata. The Stata Journal 9: 86-136.

Rose, R., 2000: How Much Does Social Capital Add to Individual Health? Social Science \& Medicine 51: 1421-1435.

Rosenberg, M., 1956: Misanthropy and Political Ideology. American Sociological Review 21: 690-695.

Rothstein, B. \& D. Stolle, 2008: The State and Social Capital: An Institutional Theory of Generalized Trust. Comparative Politics 40: 441-459.

Rothstein, B. \& D. Eek, 2009: Political Corruption and Social Trust: An Experimental Approach. Rationality and Society 21: 81-112.

Sapienza, P., A. Toldra Simats \& L. Zingales, 2013: Understanding Trust. Economic Journal 123: 13131332.

Seligman, A.B., 2000: The Problem of Trust. Princeton: Princeton University Press.

Skocpol, T., 2003: Diminished Democracy: From Membership to Management in American Civic Life. Norman: University of Oklahoma Press.

Sønderskov, K., 2011: Does Generalized Social Trust Lead to Associational Membership? Unravelling a Bowl of Well-Tossed Spaghetti. European Sociological Review 27: 419-434.

Stolle, D., 2001: "Getting to Trust": An Analysis of the Importance of Institutions, Families, Personal Experiences and Group Membership. Pp 118-133 in: P. Dekker \& E. Uslaner (eds.), Social Capital and Participation in Everyday Life. New York: Taylor \& Francis.

Stolle, D., 2002: Trusting Strangers - The Concept of Generalized Trust in Perspective. Österreichische Zeitschrift für Politikwissenschaft 31: 397-412.

Stolle, D., 2003: The Sources of Social Capital. Pp 19-42 in: D. Stolle \& M. Hooghe (eds.), Generating Social Capital: Civil Society and Institutions in Comparative Perspective. New York: Palgrave Macmillian.

Stolle, D. \& M. Hooghe (eds.), 2003: Generating Social Capital: Civil Society and Institutions in Comparative Perspective. New York: Palgrave Macmillian.

Sturgis, P. \& P. Smith, 2010: Assessing the Validity of Generalized Trust Questions: What Kind of Trust Are We Measuring? International Journal of Public Opinion Research 22: 74-92.
Sturgis, P., S. Read, P.K. Hatemi, G. Zhu, T. Trull, M.J. Wright \& N.G. Martin, 2010: A Genetic Basis for Social Trust? Political Behavior 32: 205-230.

Tocqueville, A.D., 2002 [1835]: Democracy in America. 2 vols. Hazleton: Pennsylvania State University.

Torpe, L. \& H. Lolle, 2011: Identifying Social Trust in Cross-Country Analysis: Do We Really Measure the Same? Social Indicators Research 103: 481-500.

Uslaner, E.M., 2002: The Moral Foundations of Trust. Cambridge: Cambridge University Press.

Uslaner, E.M., 2008: The Foundations of Trust: Macro and Micro. Cambridge Journal of Economics 32: 289294.

Uslaner, E.M., 2012: Measuring Generalized Trust: In Defense of the "Standard" Question. Pp 72-81 in: F. Lyon, G. Mollering \& M.N.K. Saunders (eds.), Handbook of Research Methods on Trust. Cheltenham: Edward Elgar.

Valdivieso, P. \& B. Villena-Roldan, 2014: Opening the Black Box of Social Capital Formation. The American Political Science Review 108: 121-143.

Voorpostel, M., 2010: Attrition Patterns in the Swiss Household Panel by Demographic Characteristics and Social Involvement. Swiss Journal of Sociology 36: 359-377.

Wawro, G., 2002: Estimating Dynamic Panel Data Models in Political Science. Political Analysis 10: 25-48.

Welch, M.R., D. Sikkink \& M.T. Loveland, 2007: The Radius of Trust: Religion, Social Embeddedness and Trust in Strangers. Social Forces 86: 23-46.

Westlund, H. \& F. Adam, 2010: Social Capital and Economic Performance: A Meta-Analysis of 65 Studies. European Planning Studies 18: 893-919.

Whiteley, P.F., 1999: The Origins of Social Capital. Pp 2341 in: J.W.V. Deth, , M. Maraffi, K. Newton \& P.F. Whiteley (eds.), Social Capital and European Democracy. London: Routledge.

Whiteley, P.F., 2000: Economic Growth and Social Capital. Political Studies 48: 443-466.

Woolcock, M., 2010: The Rise and Routinization of Social Capital, 1988-2008. Annual Review of Political Science 13: 469-487.

Wooldridge, J.M., 2001: Applications of Generalized Method of Moments Estimation. Journal of Economic Perspectives 15: 87-100.

Yamagishi, T. \& M. Yamagishi, 1994: Trust and Commitment in the United States and Japan. Motivation and Emotion 18: 129-166.

Yip, W., S.V. Subramanian, A.D. Mitchell, D.T.S. Lee, J. Wangc \& I. Kawachi, 2007: Does Social Capital Enhance Health and Well-Being? Evidence From Rural China. Social Science \& Medicine 64: 35-49.

Zmerli, S. \& K. Newton, 2008: Social Trust and Attitudes toward Democracy. Public Opinion Quarterly 72: $706-724$

Zmerli, S. \& K. Newton, 2011: Winners, Losers and Three Types of Trust. Pp 67-94 in: M. Hooghe, \& S. Zmerli (eds.), Political Trust. Why Context Matters. Colchester: ECPR Press. 


\section{Autorenvorstellung}

Katrin Botzen M.A. geb. 1984 in Solingen. Studium der Soziologie, Psychologie und Anglistik an der RWTH Aachen. Von 2009 bis 2010 wissenschaftliche Mitarbeiterin am Forschungsinstitut für Soziologie der Universität zu Köln. Seit 2010 Doktorandin an der Universität Bern, Schweiz. Von 2010 bis 2014 wissenschaftliche Assistentin am Lehrstuhl für Methoden der empirischen Sozialforschung des Instituts für Soziologie in Bern. In 2015 Visiting Research Student an der University of Victoria, British Columbia, Canada.

Forschungsschwerpunkte: Sozialkapital und Zivilgesellschaft, Organisationssoziologie, Quantitative Methoden Wichtigste Publikationen: Vereine in Deutschland und ihr Beitrag zum Wohlstand der Regionen (mit Axel Franzen), Soziale Welt 62: 391-413, 2011. Mir hei e Verein: Eine Studie über Vereine, Sozialkapital und Wohlstand im Kanton Bern (mit Axel Franzen), Schweizerische Zeitschrift für Soziologie 40(1): 79-98, 2014. 